\title{
A Microdigestion Procedure Directly Performed in the Autosampler Cups for the Determination of Trace Elements in Biological Samples by GF AAS
}

\author{
Reinaldo C. Campos, *,a Sergio F. Jerez Vegueria, ${ }^{a, b}$ \\ Rodrigo A. Gonçalves ${ }^{a}$ and Ângela L. R. Wagener ${ }^{a}$ \\ ${ }^{a}$ Departamento de Química, Pontifícia Universidade Católica do Rio de Janeiro, \\ CP 38097, 22453-900 Rio de Janeiro-RJ, Brazil \\ ${ }^{b}$ Instituto de Química, Universidade Federal Fluminense, 24020-150 Niterói-RJ, Brazil
}

\begin{abstract}
Um procedimento de microdigestão para a determinação de $\mathrm{Cd}$ e $\mathrm{Cu}$ em amostras biológicas por espectrometria de absorção atômica em forno de grafite (GF AAS) é descrito. Massas de até $5 \mathrm{mg}$ são pesadas diretamente na cubeta do amostrador automático e $100 \mu \mathrm{L}$ de solução digestora $\left(\mathrm{HNO}_{3}-\mathrm{H}_{2} \mathrm{SO}_{4} 1: 1 \mathrm{v} / \mathrm{v}\right.$ ou $\mathrm{HNO}_{3}$ concentrado) são adicionados. As cubetas são fechadas e a digestão é realizada a $60{ }^{\circ} \mathrm{C}$, por $12 \mathrm{~h}$, em um bloco de digestão especialmente desenhado; seguem-se a adição de $900 \mu \mathrm{L}$ de água ultrapura, a homogeneização e transferência das cubetas ao amostrador automático. O ambiente fechado e o uso de apenas um único frasco durante todo o processo minimizam os riscos de contaminação e perdas. Curvas analíticas externas, no mesmo meio do branco, mostraram-se adequadas para a calibração. A análise de nove diferentes materiais de referência certificados permitiu a avaliação da exatidão do procedimento. Os limites de quantificação na amostra original $(5 \mathrm{mg})$, calculados a partir de dez sucessivas medições do branco $(\mathrm{k}=10)$ foram 0,07 e 1,7 ou 0,02 e $0,3 \mu \mathrm{g} \mathrm{g}^{-1}$ para $\mathrm{Cd}$ e $\mathrm{Cu}$, respectivamente, usando cada uma das misturas. $\mathrm{O}$ procedimento foi utilizado, com sucesso, para a determinação de $\mathrm{Cu}$ em amostras de biópsia de fígado humano.
\end{abstract}

A microdigestion procedure for the determination of $\mathrm{Cd}$ and $\mathrm{Cu}$ in biological samples by graphite furnace atomic absorption spectrometry (GF AAS) is described. Masses up to $5 \mathrm{mg}$ are directly weighed in the autosampler cup and $100 \mu \mathrm{L}$ of the digestion solution $\left(1: 1 \mathrm{v} / \mathrm{v} \mathrm{HNO}_{3}\right.$ $\mathrm{H}_{2} \mathrm{SO}_{4}$ or concentrated $\mathrm{HNO}_{3}$ ) are added. The cups are closed and the digestion is performed, at $60{ }^{\circ} \mathrm{C}$ overnight in a specially designed digestion block. After cooling, $900 \mu \mathrm{L}$ of ultrapure water is added, the solution is homogenized and the cups are transferred to the autosampler tray. Since the digestion is performed in a sealed environment and the whole procedure uses only one flask, the risks of contamination and losses are minimized. Calibration was performed with external calibration curves, in the same medium as the reagents blank. The analysis of nine different standard reference materials permitted the assessment to the accuracy of the procedure. Considering a $5 \mathrm{mg}$ sample mass, the limits of quantification in the original samples calculated from ten successive measurements of the blank solution $(\mathrm{k}=10)$ were 0.07 and 1.7 and 0.02 and $0.3 \mu \mathrm{g} \mathrm{g}^{-1}$ for $\mathrm{Cd}$ and $\mathrm{Cu}$ respectively, using the $\mathrm{HNO}_{3}-\mathrm{H}_{2} \mathrm{SO}_{4}$ mixture or concentrated $\mathrm{HNO}_{3}$ for the digestion. The procedure was used for the determination of $\mathrm{Cu}$ in human liver biopsy samples.

Keywords: microdigestion procedure, trace analysis, graphite furnace atomic absorption spectrometry

\section{Introduction}

The sample dissolution or digestion is still the most common sample pre-treatment in total trace analysis, since a low viscosity liquid (preferably an aqueous solution) is

*e-mail: rccampos@puc-rio.br the more adequate way for presenting samples to most available instrumentation. ${ }^{1}$ The introduction of liquid samples is simpler and faster, also allowing the full automation of this step. However, when the sample amount is a limitation sample dissolution or digestion may lead to difficulties, since these procedures usually need sample amounts at the 0.1-1 g order, leading to final volumes 
from 10 to $100 \mathrm{~mL}$. Solid sampling (SS) is an alternative and techniques such as solid sampling electrothermal vaporization associated to inductively coupled plasma mass spectrometry (SS-ETV-ICP-MS) or solid sampling graphite furnace atomic absorption spectrometry (SS-GF AAS) are examples of such possibility. ${ }^{2,3}$ Solid sampling is claimed to avoid the risks of contamination and losses that are related to sample digestion, and since no dilution occurs, excellent limits of detection in the original samples can be obtained. However, typical problems related to solid sampling still impair the spread of its acceptance in routine analysis: Due to the small sample masses usually used ${ }^{4,5}$ problems related to sample non-homogeneity may be experienced; since the use of aqueous calibration solutions is not always possible, calibration problems may also be observed.

An alternative for dealing with small sample masses are microdigestion procedures. ${ }^{6-19}$ They can be performed by direct acid addition or vapor phase digestion. ${ }^{7-10,12,14,15,19-25}$ Contamination risks can be minimized if a single vessel is used for the whole procedure. . $, 8,11,15,19-23,25-30$ For instance, Sperling has proposed a microdigestion procedure for the determination of $\mathrm{Cd}$ in environmental samples. ${ }^{31} \mathrm{He}$ used $50 \mu \mathrm{L}$ of a $1+4 \mathrm{v} / \mathrm{v} \mathrm{H}_{2} \mathrm{SO}_{4}: \mathrm{HNO}_{3}$ mixture to digest $5 \mathrm{mg}$ of biological materials in $1.5 \mathrm{~mL}$ polypropylene (eppendorf) vials. The solution was then made up to $1 \mathrm{~mL}$ with deionized water before ammonium pyrrolidinedithiocarbamate (APDC) extraction and GF AAS determination in the organic extract. Later on, Campos et al. ${ }^{32}$ have used the same strategy as a comparison procedure for the analysis of small masses of solid powdered vegetable samples, but the GF AAS determination was performed directly in the aqueous solution derived from the acid digestion. An interesting variation was presented by Flores and co-workers, who determined As in $10 \mathrm{mg}$ hair samples, after microwave-assisted digestion in $1.5 \mathrm{~mL}$ polypropylene vials; determination was performed by hydride generation atomic absorption spectrometry, and the digestion flask was used as reduction vessel, as well. ${ }^{33}$ However, if GF AAS is to be used, as in the former cases, the final sample solution has still to be transferred to the autosampler cups. Thus, in order to overcome this step, the present work proposes and investigates the direct weighing and digestion of biological samples in the autosampler cups of the GF AAS instrument itself. The digestion was performed in a sealed system using a specially designed digestion block, avoiding any sample transference, aiming at minimizing contact with exogenous surfaces.

\section{Experimental}

\section{Instrumental}

The GF AAS measurements were performed in a model ZEEnit 60 (Analytik Jena, Jena, Germany) atomic absorption spectrometer, equipped with a transversally heated graphite atomizer, and an AS-52 autosampler. Cadmium and $\mathrm{Cu}$ hollow cathode lamps (Analytik Jena) operated at 228.8 and $324.8 \mathrm{~nm}$ were respectively used as line sources. The lamp currents and slits were those recommended by the manufacturer. Pin platform pyrolitically coated graphite tubes were used, as well as Zeeman effect based background correction with the 2-field mode at 0.8 T. Measurements were performed in peak area, and were the average of at least 3 replicates. The injected volumes were always $10 \mu \mathrm{L}$. An AD-4 microbalance (Perkin Elmer, Bodenseewerk, Germany, Part No. C655-001, $0.1 \mu \mathrm{g}$ sensitive) was used for the sample weighing. For the digestion, a specially designed cylindrical aluminum digestion block $(\varnothing=140 \mathrm{~mm}$; $\mathrm{h}=40 \mathrm{~mm}$ ), with 18 drilled holes $(\varnothing=14 \mathrm{~mm})$ were used. The cups stoppers were kept in place during the digestion by an aluminum cover $(\varnothing=140 \mathrm{~mm} ; \mathrm{h}=12 \mathrm{~mm})$, tightened by three screw-nuts (Figure 1). The autosampler cups (Sarstedt, Numbrecht, Germany, part number 73.641) are made of polystyrene, and the stoppers (Sarstedt, part number 65.649) are made of low density polyethylene.

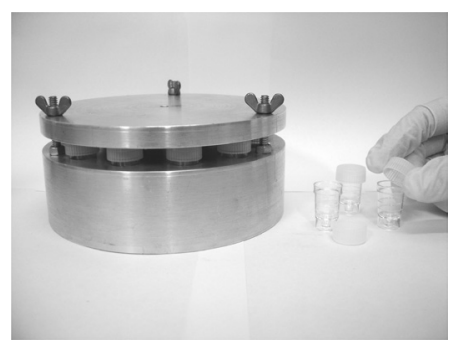

Figure 1. The digestion block (for dimensions, see text).

Materials, reagents, solutions, certified reference materials and samples

Argon 99.99\% (AGA, Rio de Janeiro, Brazil) was used as a protective and carrier gas. Ultra pure water, obtained from a Gehaka Master System apparatus (Gehaka, Sao Paulo, Brazil) was used throughout. Analytical grade $\mathrm{HNO}_{3}$ (Vetec, Rio de Janeiro, Brazil) was purified by sub boiling distillation using a teflon ${ }^{R}$ sub boiler apparatus (Hans Kuerner, Rosenheim, Germany). Sulfuric acid (Merck, Rio de Janeiro, Brazil) was of analytical reagent grade and $1000 \mathrm{mg} \mathrm{L}^{-1} \mathrm{Cd}$ and $\mathrm{Cu}$ stock solutions were respectively 
prepared by adequate dilution of Titrisol ampoules (Merck, Darmstadt, Germany) with $0.2 \%$ v/v $\mathrm{HNO}_{3}$. Calibration solutions were prepared by further convenient dilutions of the stock solutions in the same acid concentration as the digestion blanks. Two digestion solutions were used: $1+1 \mathrm{v} / \mathrm{v} \mathrm{HNO}_{3}: \mathrm{H}_{2} \mathrm{SO}_{4}$ and concentrated $\mathrm{HNO}_{3}$. Palladium nitrate $\left(10000 \mathrm{mg} \mathrm{L}^{-1}\right)$ and $\mathrm{Mg}\left(\mathrm{NO}_{3}\right)_{2}\left(10000 \mathrm{mg} \mathrm{L}^{-1}\right)$, both from Merck were used for preparing the modifier solution. A series of certified reference materials (CRMs) was analyzed and they are listed throughout the work. Two biopsy human liver samples were also analyzed. All plastic ware was washed with tap water, immersed in $10 \%$ v/v neutral Extran solution ( $48 \mathrm{~h}$ ), rinsed in sequence with tap and deionized water, and immersed in $20 \% \mathrm{v} / \mathrm{v} \mathrm{HNO}_{3}$ for, at least, $24 \mathrm{~h}$. Before handling, these materials were thoroughly rinsed with ultrapure water and oven dried at $40{ }^{\circ} \mathrm{C}$, avoiding any contact with metallic surfaces and dust contamination. Contamination was always checked up by a strict blank control.

\section{Proposed procedure}

Sample aliquots weighing between 0.5 and $5 \mathrm{mg}$ were directly weighed in the autosampler vials (conical bottom). The acid digestion solution $(100 \mu \mathrm{L})$ was then added to the vials. The cups were tightly closed with the plastic stoppers and placed in the digestion block. The cover of the digestion block was then screwed on the body of the block, pressing the stoppers and sealing the cups. The digestion block was transferred to an oven, and heated to $60{ }^{\circ} \mathrm{C}$ remaining at this temperature overnight. All the digestion was performed in a hood; afterwards, the digestion block was let to cool down to the room temperature, the cover of the digestion block was removed and the cups (still closed) were removed from the block. In this way, no oxidation of the block was observed along the experiments. The cups were opened, and $900 \mu \mathrm{L}$ of ultrapure water was added to each vial. Homogenization was achieved by aspirating/ dispensing the solution in the vials many times. This operation was manually performed with the micropipette used for adding the ultrapure water, using a unique tip for each cup. The vials were then transferred to the autosampler tray and the GF AAS analysis was performed according to the optimized graphite furnace programs displayed in Table 1. Cadmium determination was performed with the aid of $\mathrm{Pd}$ and $\mathrm{Pd}+\mathrm{Mg}$ as modifiers. The modifier masses dispensed onto the platform were $10 \mu \mathrm{g}(\mathrm{Pd})$ and $10+15 \mu \mathrm{g}$ $\left(\mathrm{Pd}+\mathrm{Mg}\left(\mathrm{NO}_{3}\right)_{2}\right)$ and the injected volumes (sample and modifier solutions) were $10 \mu \mathrm{L}$. Palladium alone was used for the samples digested with the acid mixture; $\mathrm{Pd}+\mathrm{Mg}$ when only $\mathrm{HNO}_{3}$ was used. The modifier was injected in the conventional way that is after the sample solution and before the drying steps. The water contents of the CRM samples were determined in separate aliquotes, by heating them at $105^{\circ} \mathrm{C}$ overnight. The calculations took the water content into consideration.

Table 1. GF AAS temperature programs

\begin{tabular}{|c|c|c|c|c|}
\hline Step & $\begin{array}{c}\text { Temperature / } \\
{ }^{\circ} \mathrm{C}\end{array}$ & $\begin{array}{l}\text { Ramp / } \\
\left({ }^{\circ} \mathrm{C} \mathrm{s}^{-1}\right)\end{array}$ & Hold / s & $\begin{array}{c}\text { Ar flow / } \\
\left(\mathrm{mL} \mathrm{min}{ }^{-1}\right)\end{array}$ \\
\hline 1 (drying) & 90 & 10 & 5 & 300 \\
\hline 2 (drying) & 120 & 10 & 5 & 300 \\
\hline 3 (pre-pyrolysis) & 350 & 4 & 10 & 300 \\
\hline 4 (pyrolysis) & $\begin{array}{c}800^{\mathrm{a}} / 900^{\mathrm{b}} \\
1100^{\mathrm{c}} / 1100^{\mathrm{d}}\end{array}$ & 60 & $\begin{array}{l}15^{\mathrm{a}} / 15^{\mathrm{b}} \\
20^{\mathrm{c}} / 10^{\mathrm{d}}\end{array}$ & 300 \\
\hline 5 (autozero) & $\mathrm{AZ}$ & 0 & 6 & 0 \\
\hline $6^{\mathrm{f}}$ (atomization) & $\begin{array}{l}1300^{\mathrm{a}} / 1600^{\mathrm{b}} \\
2100^{\mathrm{c}} / 2100^{\mathrm{d}}\end{array}$ & $\begin{array}{l}1300^{\mathrm{a}} / 1300^{\mathrm{b}} \\
1500^{\mathrm{c}} / 1800^{\mathrm{d}}\end{array}$ & $\begin{array}{l}6^{a} / 6^{b} \\
4^{c} / 6^{d}\end{array}$ & 0 \\
\hline 7 (cleaning) & $\begin{array}{l}2650^{\mathrm{a}} / 2650^{\mathrm{b}} \\
2500^{\mathrm{c}} / 2500^{\mathrm{d}}\end{array}$ & 1000 & 4 & 300 \\
\hline
\end{tabular}

${ }^{\mathrm{a}} \mathrm{Cd}$, after $1+1 \mathrm{HNO}_{3}+\mathrm{H}_{2} \mathrm{SO}_{4}$ digestion; ${ }^{\mathrm{b}} \mathrm{Cd}$, after $\mathrm{HNO}_{3}$ digestion; ${ }^{\mathrm{c}} \mathrm{Cu}$, after $1+1 \mathrm{HNO}_{3}+\mathrm{H}_{2} \mathrm{SO}_{4}$ digestion; ${ }^{\mathrm{d}} \mathrm{Cu}$, after $\mathrm{HNO}_{3}$ digestion; ' temperature always $=$ pyrolysis temperature; ${ }^{\mathrm{f}} \mathrm{Read}$ in this step.

\section{Results and Discussion}

\section{Temperature program optimization}

Optimum pyrolysis and atomization temperatures were obtained from pyrolysis and atomization temperatures curves performed in the blanks, prepared by the $1+9(\mathrm{v} / \mathrm{v})$ dilution of the digestion solutions $\left(1+1 \mathrm{v} / \mathrm{v} \mathrm{HNO}_{3}: \mathrm{H}_{2} \mathrm{SO}_{4}\right.$ and concentrated $\mathrm{HNO}_{3}$ ). They are displayed in Table 1 as well as other temperature programs parameters. Before the determinations, the vicinities $\left( \pm 100^{\circ} \mathrm{C}\right)$ of the pyrolysis and atomization temperatures chosen were investigated for both the calibration solutions and each kind of sample solution. This was due to the possibility of differences between set and real temperatures. This also permitted to verify the adequacy of the pyrolysis and atomization temperatures to the real samples.

\section{Calibration and figures of merit}

External calibration was performed with aqueous calibration solutions prepared using the same media as the blanks. No statistically significant difference was observed between the slopes derived from these calibration curves and those obtained from analyte addition curves, for the various matrices and the two elements studied. Correlation coefficients were always better than 0.99 and typical coefficients of variation between 1 and 3\% were observed 
if the same sample solution was analyzed in sequence $(n=5)$. The limits of detection (LODs) were calculated from 10 successive measurements of the blank solutions $(\mathrm{k}=3)$ as recommended by IUPAC. They were 0.1 and $2.5 \mu \mathrm{g} \mathrm{L}{ }^{-1}$, for $\mathrm{Cd}$ and $\mathrm{Cu}$ respectively, if the acid mixture had been used for the digestion. For the digestion with $\mathrm{HNO}_{3}$, they were 0.03 and $0.5 \mu \mathrm{g} \mathrm{L} \mathrm{L}^{-1}$. Considering sample masses of $5 \mathrm{mg}$, the limits of quantification in the original samples were 0.07 and $1.7 \mu \mathrm{g} \mathrm{g}^{-1}$ using the digestion mixture, and 0.02 and $0.3 \mu \mathrm{g} \mathrm{g}^{-1}$ using the concentrated $\mathrm{HNO}_{3}$, for $\mathrm{Cd}$ and $\mathrm{Cu}$, respectively.

\section{Accuracy}

Accuracy was assessed by the analysis of certified reference materials. They are listed in Tables 2 and 3, as well as their respective certified values and confidence ranges. Table 2 also shows the results, and their respective confidence ranges, obtained after digestion with the $1+1 \mathrm{v} / \mathrm{v} \mathrm{HNO}_{3}: \mathrm{H}_{2} \mathrm{SO}_{4}$ mixture, while Table 3 refers to the $\mathrm{HNO}_{3}$ digestion. In relation to $\mathrm{Cd}$, the digestion with the $1+1 \mathrm{v} / \mathrm{v} \mathrm{HNO}_{3}: \mathrm{H}_{2} \mathrm{SO}_{4}$ solution (Table 2) led to good agreement between found and certified values for the four CRMs that showed $\mathrm{Cd}$ values above the limit of quantification of the procedure. $\mathrm{Cd}$ values in Dogfish Muscle, Non Fat Milk Powder, Peach, Citrus and Apple Leaves were below this limit. For $\mathrm{Cu}$, its content in only one CRM was below the limit of quantification (Non Fat Milk Powder). For all other CRMs, good agreement between found and certified values was observed. For the digestion with concentrated $\mathrm{HNO}_{3}$ only (Table 3), better limits of quantification could be observed due to the lower blanks obtained. The concentrated $\mathrm{HNO}_{3}$ was purified by sub boiling distillation while this purification procedure proved to be ineffective for $\mathrm{H}_{2} \mathrm{SO}_{4}$. The lower blanks permitted the determination of $\mathrm{Cd}$ in two of the CRMs (Peach Leaves and
Citrus Leaves) that were below the limit of quantification using the previous digestion mixture. Acceptable agreement between found and certified values was verified, especially considering that their values are very close to the limit of quantification. On the other hand, low Cd recovery was now observed for Dogfish Muscle. In contrast, for $\mathrm{Cu}$, a good agreement was observed in all cases, and the new limit of quantification was low enough to permit the $\mathrm{Cu}$ determination even in the Non Fat Milk Powder CRM.

Confidence ranges of the found values larger than those correspondent to the certified values can be explained by the small sample masses used in the proposed procedure in comparison to those used in the certification of these materials. However, even in these cases the coefficients of variation of the proposed procedure are adequate for trace analysis. Note that in Tables 2 and 3 the $n=5$ value is related to the number of independent analysis performed for the same sample, which includes the sample weighing. As expected, a tendency to larger coefficients of variation was observed in the cases which concentration values were close to the limits of quantification.

\section{Application}

A significant application for the proposed procedure arose when two liver biopsy samples came to the laboratory in order to be investigated for their $\mathrm{Cu}$ content, for a possible Wilson disease diagnostic. They were presented in small pieces about $2 \mathrm{~mm}^{3}$ in size, implicating that any physical pre-treatment (grinding, homogenization) would be technically difficult and lead to prohibitive mass losses. Their very small masses also impaired the use of conventional digestion procedures. The use of direct solid sampling GF AAS would imply cutting the samples in even smaller pieces, a difficulty and risky operation, due to the

Table 2. $\mathrm{Cd}$ and $\mathrm{Cu}$ determination in CRMs by the proposed procedure using the $1+1 \mathrm{v} / \mathrm{v} \mathrm{H}_{2} \mathrm{SO}_{4}: \mathrm{HNO}_{3}$ solution for the sample digestion: Found ( $\mathrm{n}=5$ ) and certified values in $\mu \mathrm{g} \mathrm{g}^{-1}$. Uncertainties are $95 \%$ confidence intervals

\begin{tabular}{lcccc}
\hline CRM & & Cd & & Cu \\
& Certified & Found & Certified & Found \\
\hline DORM-2 Dogfish Muscle, NRC Canada & $0.043 \pm 0.008$ & $<$ LOQ & $2.34 \pm 0.16$ & $2.4 \pm 0.5$ \\
DOLT-3 Dogfish Liver, NRC, Canada & $19.4 \pm 0.6$ & $21.4 \pm 0.6$ & $31.2 \pm 1.0$ & $31.4 \pm 0.6$ \\
TORT-2, Lobster Hepatopancreas, NRC & $26.7 \pm 0.6$ & $29.9 \pm 2.9$ & $106 \pm 10$ & $110 \pm 11$ \\
NIST 1577a, Bovine Liver & $0.44 \pm 0.06$ & $0.43 \pm 0.03$ & $158 \pm 7$ & $160 \pm 13$ \\
NIST 1549, Non Fat Milk Powder & $0.0005 \pm 0.0002$ & $<$ LOQ & $0.7 \pm 0.1$ & $<.7 \pm 0.4$ \\
NIST 1547, Peach Leaves & $0.026 \pm 0.003$ & $<$ LOQ & 3.6 & $3.61 \pm 0.06$ \\
NIST 1572, Citrus Leaves & $0.03 \pm 0.01$ & $<$ LOQ & $16.5 \pm 1.0$ & $16.8 \pm 7.2$ \\
NIST 1515, Apple Leaves & $0.013 \pm 0.002$ & $<$ LOQ & $5.64 \pm 0.24$ & $6.2 \pm 1.4$ \\
NIST 1573a, Tomato Leaves & $1.52 \pm 0.04$ & $1.6 \pm 0.1$ & $4.70 \pm 0.14$ & $4.1 \pm 0.6$ \\
\hline
\end{tabular}


Table 3. $\mathrm{Cd}$ and $\mathrm{Cu}$ determination in CRMs by the proposed procedure using concentrated $\mathrm{HNO}_{3}$ for the sample digestion: Found $(\mathrm{n}=5)$ and certified values in $\mu \mathrm{g} \mathrm{g}^{-1}$. Uncertainties are $95 \%$ confidence intervals

\begin{tabular}{lcccc}
\hline CRM & \multicolumn{2}{c}{ Cd } & & Cu \\
& Certified & Found & Certified & Found \\
\hline DORM-2 Dogfish Muscle, NRC, Canada & $0.043 \pm 0.008$ & $0.022 \pm 0.008$ & $2.34 \pm 0.16$ & $2.5 \pm 0.2$ \\
DOLT-3 Dogfish Liver NRC, Canada & $19.4 \pm 0.6$ & $21.9 \pm 1.4$ & $31.2 \pm 1.0$ & $30.4 \pm 2.1$ \\
TORT-2 Lobster Hepatopancreas, NRC & $26.7 \pm 0.6$ & $29.0 \pm 1.0$ & $106 \pm 10$ & $102 \pm 5$ \\
NIST 1577a, Bovine Liver & $0.44 \pm 0.06$ & $0.45 \pm 0.05$ & $158 \pm 7$ & $150 \pm 6$ \\
NIST 1549, Non-Fat Milk Powder & $0.0005 \pm 0.0002$ & $<$ LOQ & $0.7 \pm 0.1$ & $0.9 \pm 0.2$ \\
NIST 1547 Peach Leaves & $0.026 \pm 0.003$ & $0.033 \pm 0.005$ & $3.7 \pm 0.4$ & $3.7 \pm 0.2$ \\
NIST 1572 Citrus Leaves & $0.03 \pm 0.01$ & $0.035 \pm 0.02$ & $16.5 \pm 1.0$ & $15.5 \pm 1.8$ \\
NIST 1515 Apple Leaves & $0.013 \pm 0.002$ & $<$ LOQ & $5.64 \pm 0.24$ & $6.0 \pm 0.6$ \\
NIST 1573a Tomato Leaves & $1.52 \pm 0.04$ & $1.47 \pm 0.02$ & $4.70 \pm 0.14$ & $4.8 \pm 0.2$ \\
\hline
\end{tabular}

very small sample size. Thus, the samples were analyzed as they were received: Each small piece was directly introduced and weighed in the cup for digestion. They weighed 5.222 and $5.960 \mathrm{mg}$ (wet weight), respectively. They were submitted to the proposed microdigestion procedure, using the $1+1 \mathrm{v} / \mathrm{v} \mathrm{HNO}_{3}: \mathrm{H}_{2} \mathrm{SO}_{4}$ acid mixture, and $\mathrm{Cu}$ values of 11 and $38 \mu \mathrm{g} \mathrm{g}^{-1}$, wet weight were found in the two biopsy samples, respectively. A parallel Bovine Liver CRM analysis was run, for quality assurance leading to good agreement between the found and certified value.

\section{Conclusions}

The proposed method proved to be feasible for the digestion of different kinds of biological samples. Good agreement between found and certified values using the $1+1 \mathrm{v} / \mathrm{v} \mathrm{HNO}_{3}: \mathrm{H}_{2} \mathrm{SO}_{4}$ digestion mixture was observed in the determination of $\mathrm{Cd}$ in those investigated CRMs that presented $\mathrm{Cd}$ values above the limit of quantification. The digestion with concentrated $\mathrm{HNO}_{3}$ alone led to poorer $\mathrm{Cd}$ recoveries in the analysis of Dogfish Muscle. However, it permitted the assessment of less concentrated CRMs due to lower limit of quantification found in this case, a consequence of the lower blank. For $\mathrm{Cu}$, good agreement between found and the certified values was observed in all investigated CRMs by both digestion procedures. However, the digestion with $\mathrm{HNO}_{3}$ also permitted the assessment to lower concentrations due to the lower blanks observed. These results underline the importance of a detailed optimization of the digestion mixture composition for a full exploitation of the proposed procedure. Concerning the background attenuation, it was always comfortably in the range of the background corrector.

The proposed digestion procedure is simple, performed in a closed environment, and actually uses only one vessel from weighing till the instrumental measurement, minimizing the risks of contamination or losses. The small size of the digestion vessel (the autosampler cup, itself) makes it possible to design small heating blocks with a large number of places. These blocks are easy to handle, heat in normal ovens, and cool down in a short time, due to their relatively small mass. The final sample solution homogenization is easily performed with the same automatic pipette used for making up the final volume, and the cups are ready to be transferred to the autosampler tray. The temperature of the digestion procedure could not be increased, otherwise the autosampler cups would deform, impairing their proper adjustment in the autosampler tray. This led to a somewhat large digestion time. However, the possibility of batches with a large number of places can compensate for this disadvantage if a large number of samples are to be analyzed. The investigation of other digestion mixtures may also enlarge the applicability of the method. The limits of quantification were low enough to permit $\mathrm{Cu}$ determination in all samples and $\mathrm{Cd}$ determination in all but two CRMs. To the best of our knowledge, this is the first really one vessel digestion-instrumental determination procedure described for GFAAS in the literature. The method also aligns itself with the principles of a green analytical methodology. ${ }^{34,35}$ It is important to note that certified values and their ranges in certified reference materials are calculated for sample masses much larger than those used in the present work. Thus one can expect that an important contribution to the coefficients of variation presently found is related to the sample non homogeneity, due to the small masses used. However, even with such low masses, the investigated CRMs have shown themselves sufficient homogeneous to permit acceptable coefficient of variations in trace analysis. This is also observed in other micro sampling techniques, such as solid sampling GF AAS. ${ }^{36-42}$ 


\section{References}

1. Butler, O. T.; Cook, J. M.; Harrington, C. F.; Hill, S. J.; Rieuwerts, J.; Miles, D. L.; J. Anal. At. Spectrom. 2006, 21, 217.

2. Resano, M.; Aramendia, M.; Devos, W.; Vanhaecke, F.; J. Anal. At. Spectrom. 2006, 21, 891.

3. Vale, M. G. R.; Oleszczuk, N.; dos Santos, W. N. L.; Appl. Spectrosc. Rev. 2006, 41, 377.

4. Kurfürst, U.; Appl. Spectrosc. Rev. 1991, 63, 1205.

5. Belarra, M. A.; Resano M.; Castillo, J. R.; J. Anal. At. Spectrom. 1998, 13, 489 .

6. Croteau, M.; Hare, L; Tessier, A.; Can. J. Fish. Aquat. Sci. 2001, $58,1737$.

7. Barkacs, K.; Varga, A.; Gál-Solynos, Zaray, G.; J. Anal. At. Spectrom. 1999, 14, 577.

8. Araújo, G. C. L.; Nogueira, A. R.; Nóbrega, J. A.; Microchim. Acta 2004, 144, 81.

9. Dash, K; Thangavel, S.; Dhavile, S. M.; Rao, S. V.; Chaurasia, S. C.; Arunachalam; Anal. Chim. Acta 2005, 546, 229.

10. Amarasiriwardena, D.; Analyst 1994, 119, 1017

11. Nieuwenhuize, J.; Poley-Vos, C. H.; Goud, A.; Hemminga, M. A.; At. Spectrosc. 1988, 9, 204.

12. Dombovári, J.; Becker, J. S.; Dietze, H. J.; Fresenius J. Anal. Chem. 2000, 367, 407.

13. Anderson, K.; At. Spectrosc. 1996, 17, 30.

14. Krushevska, A.; Waheed, S.; Nóbrega, J. A.; Amarisiriwardena, D.; Barnes, R. M.; Appl. Spectrosc. 1998, 52, 205.

15. Bohlen, A.; Klockenkamper, R.; Messerschimidt, J.; Alt, F.; Anal. Chim. Acta 2002, 451, 279.

16. Silva, M. M.; Vale, M. G. R.; Damin, I. C. F.; Welz, B.; Mandaji, M.; Fett, J. P.; Anal. Bioanal. Chem. 2003, 377, 165.

17. Marcó, L. M; Capote, T.; Hernández, C.; Greaves, E. D.; Spectrochim. Acta 2001, 56B, 2187.

18. Cain, D. J.; Buchwalter, D. B.; Luoma, S. N.; Environ. Toxicol. Chem. 2006, 25, 1042.

19. Araújo, G. C. L.; Nogueira, A. R. A.; Nóbrega, J. A.; Analyst 2000 , 125,1861 .

20. Dash, K.; Thangevel, S.; Dhavile, S. M.; Chandrasekaran, K; Chaurasia, S. C.; At. Spectrosc. 2003, 24,143.

21. Eilola, K.; Peramaki, P.; Analyst 2003, 128, 194.
22. Czégény, Z.; Berente, B.; Óvári, M.; Tapia, M. T.; Záray. G.; Microchem. J. 1998, 59, 100.

23. Eilola, K.; Peramaki, P.; Fresenius J. Anal. Chem. 2001, 369, 107.

24. Nóbrega, J. A.; Trevizan, L. C.; Araújo, G. C. L.; Nogueira, A. R. A.; Spectrochim. Acta 2002, 57B, 1855.

25. Niemela, M.; Kola, H.; Eilola, K.; Peramaki, P.; J. Pharm. Biomed. Anal. 2004, 35, 33.

26. Silva, W. G. P.; Campos, R. C., Miekeley, N.; Anal. Lett. 1998, 31, 1061.

27. Momen, A.; Zachariadis, G. A.; Anthemidis, A. N.; Stratis, J. A.; Anal. Chim. Acta 2006, 565, 81.

28. Dhindsa, H. S.; Battle, A. R.; Mierzwa, J.; Fresenius J. Anal. Chem. 1998, 362, 374.

29. Padilla, L. K.; Anderson, K. A.; Chemosphere 2004, 49, 575.

30. Dierenfeld, E. S.; tkinson, S.; Craig, M.; Walker, K. C.; Strich, W. J.; Clauss, M.; Zoo Biol. 2005, 24, 51.

31. Sperling, K. R. In Fortschiritte in der Atomspektrometrischen Spurenanalytik; Welz, B., ed., VCH: Weiheim, Germany, 1984, p. 385.

32. Campos, R. C.; Curtius, A. J.; Berndt, H.; J. Braz. Chem. Soc. 1990, 1,66 .

33. Flores, E. M. M.; Saidelles, A. P.; Barin, J. S. ; Mortari, S. R.; Martins, A. F.; J. Anal. At. Spectrom. 2001, 16, 1419.

34. Lawrence, H. K.; Gron, L.U.; Young, J. L.; Chem. Rev. 2007, 107, 2695.

35. Armenta, S.; Garrigues, S.; de la Guardia, M.; Trends Anal. Chem. 2008, 27, 197.

36. Nowka, R.; Müller, H.; Fresenius J. Anal. Chem. 1997, 359, 132.

37. Silva, M. M.; Vale, M. G. R.; Damin, I. C. F.; Welz, B.; Mandaji, M.; Fett, J. P.; Anal. Bioanal. Chem. 2003, 377, 165.

38. Resano, M.; Garcia-Ruiz, E.; Vanhaecke, F.; Crespoband, C.; Belarra, M. A.; J. Anal. At. Spectrom. 2004, 19, 958.

39. Kurfurst, U.; Rehnert, A.; Muntau, H.; Spectrochim. Acta 1996, $57 B, 229$.

40. Ribeiro, A. S.; Vieira, M. A.; da Silva, A. F.; Borges, D. L. G.; Welz, B.; Heitmann, U.; Curtius, A. J.; Spectrochim. Acta 2005, 60B, 693 .

41. Resano, M.; Briceno, J.; Aramend, M.; Belarra, M.A.; Anal. Chim. Acta 2007, 582, 214.

42. Detcheva, A.; Grobecker, K. H.; Spectrochim. Acta 2006, 61B, 454. 